This report was prepared as an account of work sponsored by an agency of the United States Government. Neither the United States Government nor any agency thereof, nor any of their employees, makes any warranty, express or implied, or assumes any legal liability or responsibility for the accuracy, completeness, or usefulness of any information, apparatus, product, or process disclosed, or represents that its use would not infringe privately owned rights. Reference herein to any specific commercial product, process, or service by trade name, trademark, manufacturer, or otherwise does not necessarily constitute or imply its endorsement, recommendation, or favoring by the United States Government or any agency thereof. The views and opinions of authors expressed herein do not necessarily state or reflect those of the United States Government or any agency thereof.

\title{
A TECHNIQUE TO ACHIEVE UNIFORM STRESS DISTRIBUTION IN COMPRESSIVE CREEP TESTING OF ADVANCED CERAMICS AT HIGH TEMPERATURES
}

\author{
Kenneth C. Liu, Christopher O. Stevens, and Charles R. Brinkman \\ Oak Ridge National Laboratory \\ Metals and Ceramics Division \\ Oak Ridge, Tennessee 37831-6155 USA
}

Nicholas E. Holshauser

North Carolina A \& T State University

Department of Mechanical Engineering

Greensboro, North Carolina 27411 USA

\begin{abstract}
A technique to achieve stable and uniform uniaxial compression is offered for creep testing of advanced ceramic materials at elevated temperatures, using an innovative self-aligning load-train assembly. Excellent load-train alignment is attributed to the inherent ability of a unique hydraulic universal coupler to maintain self-aligning. Details of key elements, design concept, and principles of operation of the self-aligning coupler are described. A method of alignment verification using a strain-gaged specimen is then discussed. Results of verification tests indicate that bending below $1.5 \%$ is routinely achievable with the use of the load-train system. A successful compression creep test is demonstrated using a dumb-bell shaped silicon nitride specimen tested at $1300^{\circ} \mathrm{C}$ for a period in excess of $4000 \mathrm{~h}$.
\end{abstract}

\section{INTRODUCTION}

Design of ceramic structural components for long-term use at high temperatures requires the knowledge of creep behavior in both tension and compression. Because of some experimental difficulties associated with uniaxial testing of brittle materials at elevated temperatures, bend testing methods have been used extensively to investigate mechanical properties of ceramic materials. Lack of appropriate equipment to achieve good load-train alignment, limited research material volume, low specimen cost, and ease of testing are other reasons that made bend testing methods attractive. Drawbacks are that test results do not directly yield intrinsic time-dependent material properties, such as uniaxial data obtained from specimens tested directly in tension and/or in compression. Therefore, data interpretation must be performed based on assumptions to calculate stress and strain which have been shown to be invalid under creep conditions (Anderson et al., 1975; Cohrt et al., 1985; Chuang et al., 1988) because the internal stress distribution under bending changes with time resulting in shifting of the neutral axis plane and skewing the stress distribution.
Uniaxial tensile creep data are now commonly available, but compressive creep data are still sparsely in existence due to lack of general interest and some experimental difficulties uniquely associated with compressive testing. Compressive specimens are usually small and short to avoid instability. This in turn produces small displacement that demands high resolution from the displacement measurement system. Nonuniform deformation occurring at the ends of the short specimen due to the barreling effect further compounds the problems.

Despite the known problems, the methods used in compressive testing remain elementary, basically using two parallel platens to compress a short cylindrical specimen (Debschütz et al., 1993). This testing method may be acceptable for testing metallic alloys, which are in general ductile. A review of compressive testing methods (Birch et al., 1976; Lankford, 1977; Sines and Adams, 1978; Tracy, 1987) and recent in-house exploratory studies reveal that conventional methods are inappropriate for testing brittle materials because advanced engineering ceramics in general exhibit much higher strength, higher elastic modulus, and lower ductility at high temperatures compared to those of metallic alloys. Therefore, a new testing technique is needed to ensure a high degree of stress uniformity as well as stability.

A new load-train for compressive creep testing capable of testing ceramic materials at elevated temperature as high as $1500^{\circ} \mathrm{C}$ has been developed. Results of verification tests indicate that the self-aligning universal coupler (Liu and Brinkman, 1986) being adopted in the loadtrain was capable of minimizing the deleterious specimen bending below $1.5 \%$ at the intended maximum loading condition. To complete the high temperature testing capabilities, a laser-based extensometer was used to measure creep strain directly from the specimen gage section with the aid of two intricate fiducial flags attached to the specimen.

\section{SPECIMENS}

Two types of compressive specimens are widely used: (1) a
"The submitted manuscript has been authored by a contractor of the U.S. Government under contract No. DEAC05-84OR2 1400. Accordingly, the U.S. Government retains a nonexclusive. rayalty-free license to publish or reproduce the published form of this contribution, or allow others to do so, for U.S. Government purposes." 


\section{DISCLAIMER}

Portions of this document may be illegible in electronic image products. Images are produced from the best available original document. 
uniform-diameter cylindrical specimen and (2) a dumb-bell shaped specimens having a short uniform gage section, as shown in Fig. 1. The diameter of test section varies nominally from 3 to $6 \mathrm{~mm}$, and the ratio of the height $(h)$ to diameter $(d)$ for the uniform gage section varies also in the range 1.5 to 2.5 . The advantages of using straight cylindrical specimens (Fig. 1a) are: (1) low cost, (2) small material volume, and (3) no need for special end fixturing. However, this type of specimen can introduce difficulties of alignment when small diameter specimens are used to minimize applied load for high strength materials. Other problems are buckling when $h / d$ ratio is large and barrelling when the ratio is low. A small specimen diameter may indent the platens, resulting in incorrect strain measurement when extensometer rods are attached to the platens. Protective load blocks and pads are inserted between the specimen end and platen to avoid the damage.

The problems associated with cylindrical specimen testing can be overcome by using the dumb-bell shaped specimen shown in Fig. 1 b. In this case, both ends of a straight cylinder are extended and enlarged. A smooth transition between the gage section and the enlarged end is preferred in order to minimize inherent stress concentration occurring at the end of the gage section. Ideally, a large transition radius is desirable. However, a long specimen is prone to buckling. When a small transition radius is used, a $h / d$ ratio should be increased to $\sim 4$ so that the middle section of $\sim 2.5 d$ length remains uniformly stressed. A dumb-bell specimen (Fig. 1b) having a $h / d$ ratio of $4 d$, a transition radius of $2 d$, and an end diameter of $2.5 d$ with a total length of $57 \mathrm{~mm}(=9 d)$, which is substantially longer than those used by others, have been successfully tested without buckling at $1300^{\circ} \mathrm{C}$ with an applied stress of $250 \mathrm{MPa}$. Because of the long uniform gage section, strain can be measured directly from the mid portion $(3 d=20 \mathrm{~mm}$ ) of the uniform gage section.

\section{SELF-ALIGNED LOAD-TRAIN FOR COMPRESSIVE TESTING}

A self-aligned load-train has been successfully developed for uniaxial tensile testing of brittle materials at high temperatures. Key to the successful development is the in-house developed hydraulic universal coupler (Fig. 2) which is capable of self-aligning its central axis unambiguously with the load-train axis. The self-aligning universal coupler is also utilized in the load-train for compression testing. Therefore, a brief description of internal mechanisms, operational features and principles of operation may facilitate later discussions.

The universal coupler consists basically of two major components: a hydraulic housing assembly (1) and a pull rod assembly (10). The pull rod assembly is turned over in the reversed direction and used as a push rod for compression testing. Inside the housing block (1) are eight built-in miniature hydraulic piston assemblies equally spaced on a circle. The cutout view of a hydraulic piston assembly shows an O-ring seal (5) and a piston (6) with a long stem being guided by a ball-bearing bushing (7). At the bottom of the oil chamber (4) is a vertical hole which is connected to a manifold (2). The oil chambers are therefore interconnected by the manifold. The piston assembly is secured in place by a snap ring (8), as shown in the front assembly near the lower end of the specimen (16).

For tensile testing, a buttonhead specimen (16) is directly connected to the metal pull rod assembly (10), using tapered split collets (14) and a matching metal plug (15). This gripping method

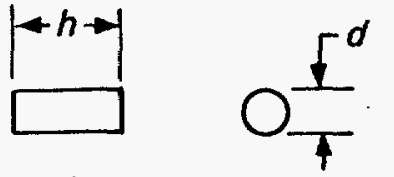

(a)

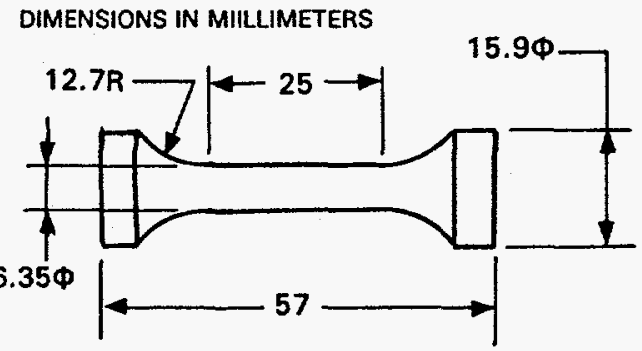

(b)

FIG. 1 - SPECIMENS USED IN COMPRESSIVE TESTING: (a) A CYLINDRICAL SPECIMEN AND (b) A DUMB-BELL SPECIMEN.

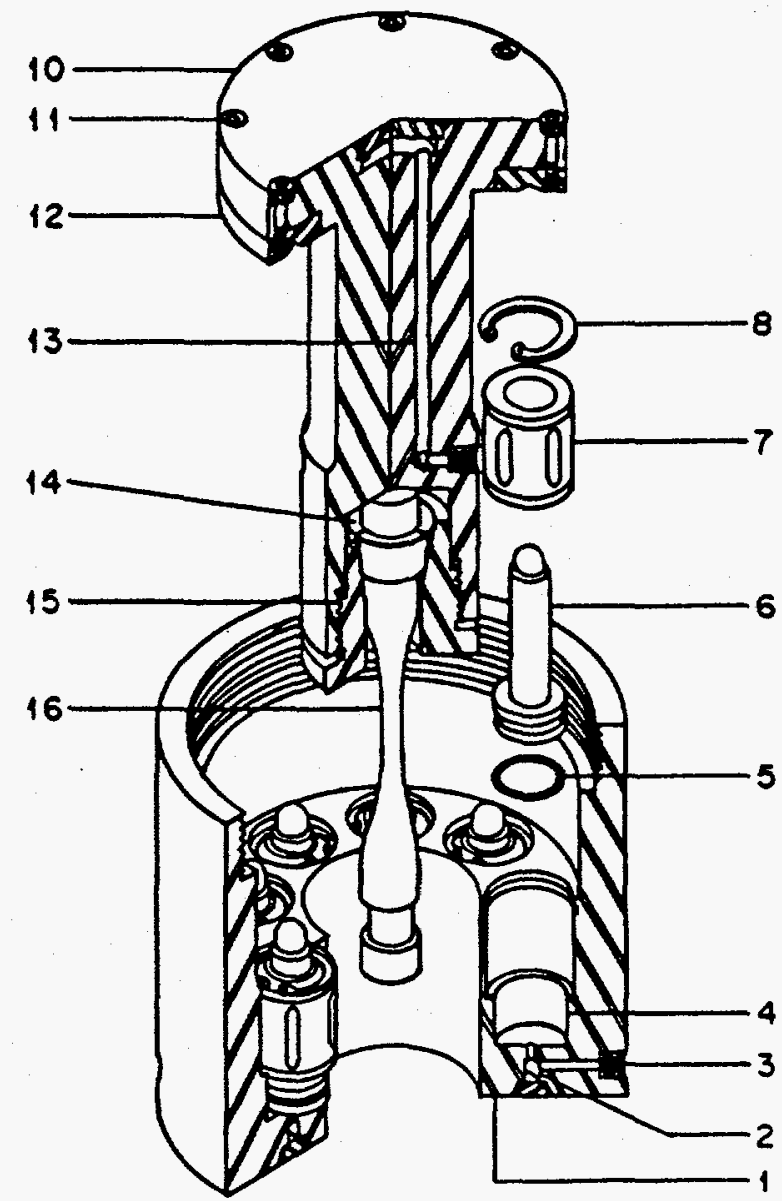

FIG. 2 - DETAILS OF THE SELF-ALIGNING UNIVERSAL COUPLER USED IN TENSILE TESTING. 
provides good concentricity between the pull rod and specimen and reliable specimen gripping. A concentrically $\mathrm{V}$-grooved circular ring (12) made of tempered steel is attached to the rod side of the disc head (10) by eight small screws (11). The tensile load-train is assembled by slipping the pull rod assembly into the center hole of the housing with the grooved ring (12) resting on the piston-rod ends. A cover plate (not shown) completes the assembly. For tensile testing, two couplers are required one at each end of the specimen.

The universal coupler is designed based on basic principles of hydrostatics and mechanics. To best describe the operational principle, a schematic diagram shown in Fig. 3 will be employed. The center arrow " $P$ " represents the specimen load, which is counterbalanced by a circular array of short arrows labeled as $R_{1}, R_{2}$, $\ldots, \mathbf{R}_{\mathbf{8}}$ symbolizing reacting forces of the eight piston assemblies. Two conditions must be met in order to achieve perfect concentric loading (i. e., zero eccentricity $\delta_{x}=\delta_{y}=0$ ). The first condition requires that all reacting forces must be equal in magnitude. Since the pistons are hydraulically interconnected through the manifold, the specimen load " $\mathrm{P}$ " must be equally distributed to all of the pistons. The second condition requires that the reaction forces representing the positions of the pistons must be equally spaced on a circle. Any deviations from the ideal conditions result in some eccentricity. A previous evaluation indicated that an eccentricity less than $25 \mu \mathrm{m}$ can be achieved.

A schematic of a load-train assembly is shown in Fig. 4 (parts identified by letters) for compressive creep testing of ceramic materials at high temperatures. For compression testing, the pull rod assembly (part 10 in Fig. 2) is tumed over and used as a push rod. To seat the disc head concentrically on the piston assembly, the $V$-grooved ring (J, part 12 in Fig. 2) is attached to the flat side of the disc head. For elevated temperature testing use, the long metallic pull rod is shortened almost to the root and used as a compression anvil $(\mathrm{H})$ which secures a ceramic push rod (G) having a diameter of $32 \mathrm{~mm}$.

Only a single universal coupler $(\mathrm{K})$ is used in the load-train for compressive testing. The universal coupler is directly connected to a load cell (L) which in turn is connected to a ram $\operatorname{rod}(\mathrm{N})$. To maintain the axiality of the ram rod, a guide bar $(M)$ is attached directly below the load cell. The guide bar has a teflon bushing at each wing guided by the load posts. The top push rod assembly ( $B$ and $D$ ) is the same as the bottom assembly, except that the upper compression anvil (B) is connected to the upper platen by a mechanical universal joint and leveled by four tumbuckles (A) spaced equally on a circle. The upper push rod assembly is aligned with the lower assembly with the aid of a strain gaged dummy specimen. The method of alignment will be discussed later. The compression specimen $(F)$ is seated concentrically with both push rods using a centering cup not shown in Fig. 4. Only the specimen and part of the ceramic push rods are enclosed in the furnace (C), and both of the compression anvils are water-cooled.

\section{OPTICAL EXTENSOMETER}

Compression strain is measured using a commercial laser-based optical extensometer (LaserMike Model 162-100) capable of $0.3 \mu \mathrm{m}$ resolution and accuracy of $1 \mu \mathrm{m}$ for applications in ambient temperature. However, both the resolution and accuracy degrade as temperature increases in the range above $1000^{\circ} \mathrm{C}$. The extensometer measures the clearance between the two fiducial flags $(E$, short

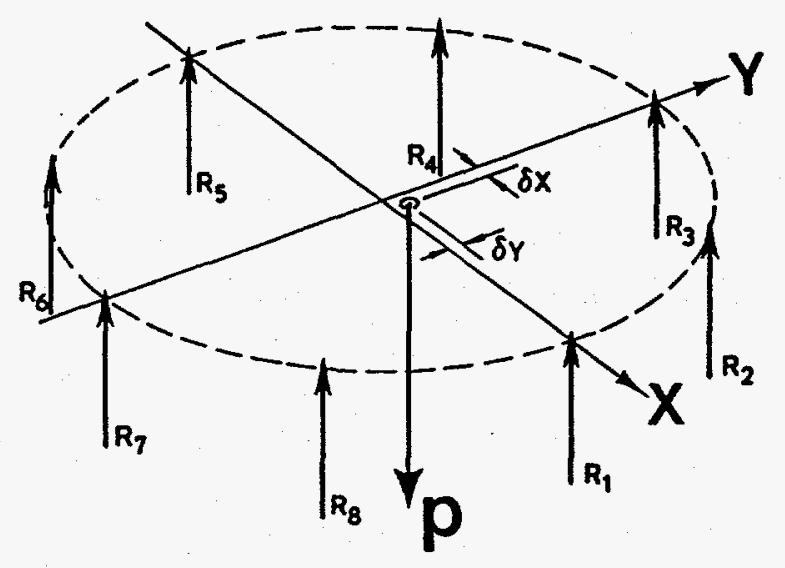

FIG. 3 - A SCHEMATIC DIAGRAM ILLUSTRATING THE DESIGN CONCEPTS OF THE SELF-ALIGNING UNIVERSAL COUPLER SHOWN IN FIG. 2.

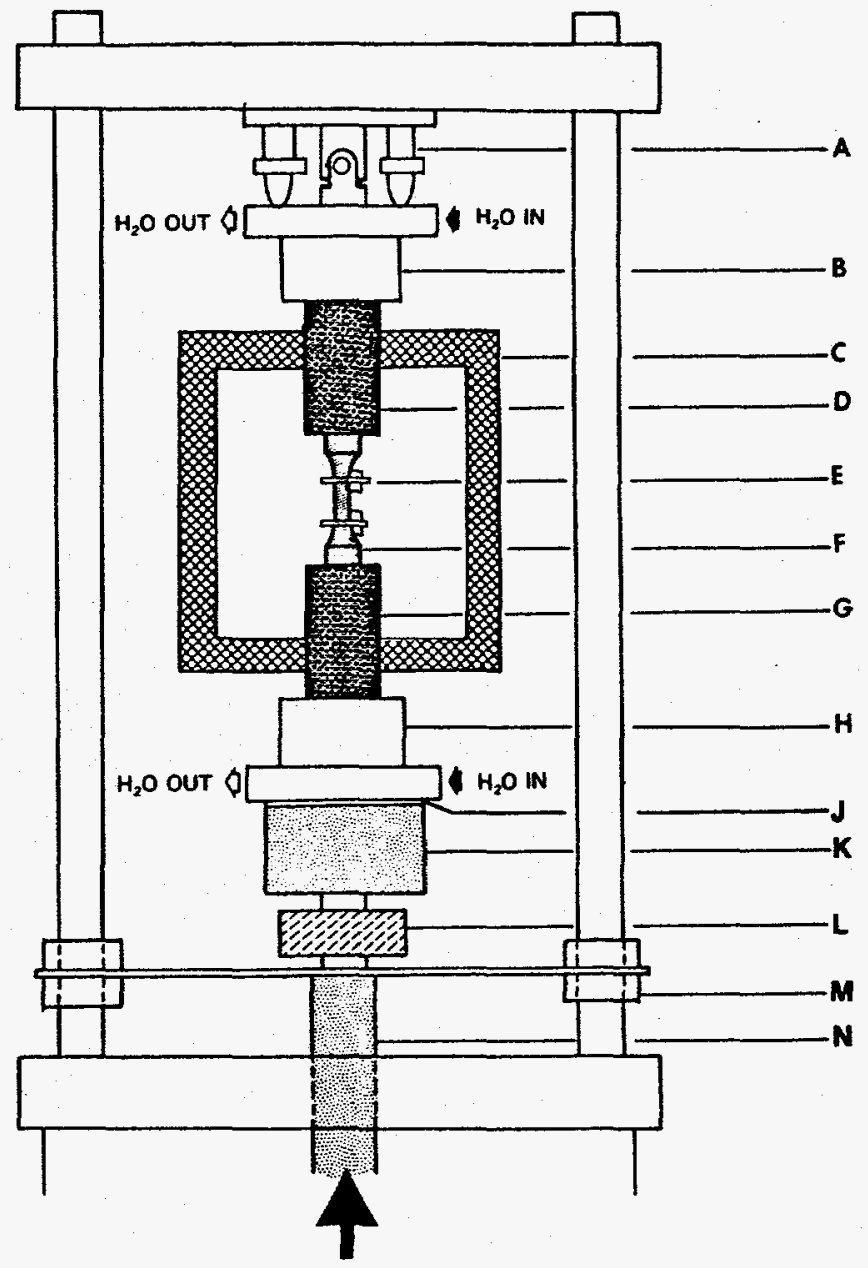

FIG. 4 - A SCHEMATIC DIAGRAM OF A LOAD-TRAIN ASSEMBLY FOR COMPRESSIVE TESTING OF CERAMIC MATERIALS AT HIGH TEMPERATURES. 
vertical pieces) attached to the side of the gage section and held by a $C$-shaped clip ( $E$, horizontal piece) visible in Fig. 4. Two pairs of the fiducial flags and a pair of C-clips are shown in Fig. 5. Both the flags and C-clips are preferably made of the specimen material or the same type of ceramic materials. One end of the flag is beveled, and the side to be mounted on the specimen is V-grooved, as shown in the bottom set of the flags. Ridges on both sides of the groove are ground from the beveled end to $\sim 3 \mathrm{~mm}$ from the unbeveled end. The unground section is directly attached to the gage section of the test specimen. With the aid of the V-groove, the flags can be secured rather easily on a curved surface and aligned with the specimen axis. A shallow notch is provided at the back side of the high ridges, visible in the other set of the flags shown in Fig. 5, to facilitate the final step of installation by the C-clip which clamps the flag on the specimen. The distance between the midpoints of the high ridge section is defined as the gage length, and the average strain within the gage section is calculated from the change of the gage length, i.e., the change of the clearance between the flags.

A schematic diagram of a laser-based extensometer is shown in Fig. 6. A light source generates a collimated laser beam which scans vertically from the bottom-up to form a thin ribbon of laser light passing through a slit cut in the furnace wall and then the center line of the flags. The light passing through the opening between the flags exits through a second slit and falls on a photo-detector positioned behind the specimen. The time required to sweep across the opening between the two flags and the sweeping speed determine the size of the opening. It must be noted that strain is calculated from the change of the opening size with respect to the gage length defined in the preceding section. Because the strain is measured on one side of the specimen, stringent specimen alignment is required to warrant the accuracy of strain measurement.

\section{ALIGNMENT OF LOAD-TRAIN ASSEMBLY}

Inherent problems associated with compressive testing such as (1) nonparallel specimen ends, (2) nonparallel compression interfaces, (3) off-center specimen seating, and (4) buckling are all related to loadtrain alignment. Off center specimen seating can be largely eliminated by the use of a shallow centering cup having a concentric hole in the bottom. The cup fits snugly on the end of the push rod and the center hole seats the specimen. The following procedure is intended to correct the nonparallel compression interfaces in order to avoid specimen bending and eventual buckling failure. The use of straingaged verification specimen with slight nonparallel ends (or angularity) will be discussed later.

Alignment of the load-train was accomplished in two steps. First, preliminary alignment was performed with a short cylindrical block having the same diameter as the ceramic push rods and the same height of a compressive test specimen (32-mm diam by $32-\mathrm{mm}$ length). With the cylinder being lightly compressed between the two push rods, reasonably good alignment can be achieved by adjusting the four turnbuckles (part A in Fig. 4). Alignment of the push rods was checked with a long steel ruler ( $\sim 0.5 \mathrm{~m}$ long) having a straight edge. At this juncture, the alignment was still coarse and needed improvement. Misalignment was indicated when a light thrust applied to the side of the cylinder caused it to swing out of the load-train assembly. The rotational axis indicated the location of the lowest point between the two compressive interfaces. This information was

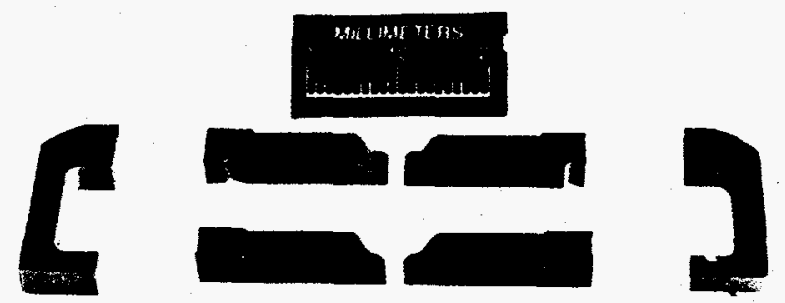

FIG. 5 - DISASSEMBLED FIDUCIAL FLAGS, SHOWING AN EXTRA PAIR OF WEDGE PARTS FOR DETAILS.

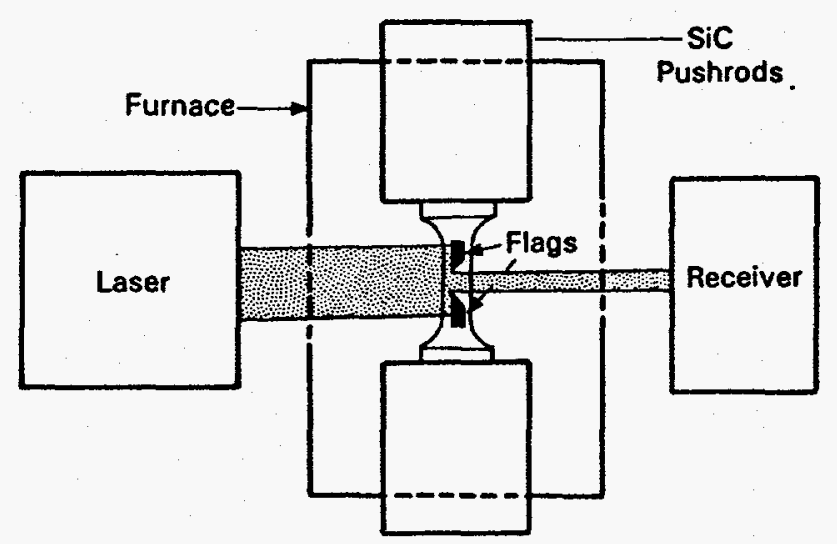

\section{FIG. 6 - A SCHEMATIC DIAGRAM OF A LASER-BASED OPTICAL EXTENSOMETER.}

used to bring the push rods in alignment by adjusting the turnbuckles. The procedure was repeated until the cylinder virtually locked in the center position.

Following the preliminary alignment, a fine alignment must be performed with a strain-gaged dummy specimen. A dummy specimen having the same geometry of the compressive specimen was fabricated from a high-strength 7075-T6 aluminum. Four strain gages were instrumented on the surface of the gage section at the midlength and equally spaced around the circumference.

To minimize the specimen and strain gage biases, the load-train is usually aligned and checked with the strain-gaged specimen being rotated through a complete $360^{\circ}$ cycle at a $90^{\circ}$ increment as outlined in ASTM Standard Test Methods C1273-94 (ASTM, 1995). To facilitate the following discussion, four fixed positions were assigned to the upper push rod as "A, B, C, and D." The side facing an observer standing in front of the load-train was designated as position $A$, and the far side from the observer as position $C$. The side facing toward the right side of the observer was designated as position $B$, and the opposite side as position D. To avoid confusion, numbers from 1 to 4 were used to designate the strain gages, with No. 1 being selected arbitrarily and the others following the position sequence.

The first alignment verification test was initiated with gage No. 1 at position A, gage No. 2 at position B, and so forth. The dummy specimen was loaded to $-2.2 \mathrm{kN}$, which was well within the elastic range of the material, and four sets of load-strain data were acquired simultaneously as the specimen was loaded and unloaded. The alignment test was repeated each time the specimen was rotated $90^{\circ}$. The acquired data were then analyzed to determine the location where 
the line of resultant force intersects with the strain gage plane, as shown in Fig. 7. The eccentricity, i.e., the distance between the resultant force and the center axis of the specimen (coordinate origin), is exaggerated in Fig. 7 for illustrative purpose.

When the resultant force is located indiscriminately on different quadrants as the alignment specimen rotates, as illustrated in the top row of Fig. 7, the indication is that the load-train is not properly aligned. Ideal alignment would be when the resultant force is on the coordinate origin regardless of the specimen orientation. This situation would rarely occur unless the verification specimen is geometrically flawless and the strain gages are identical and bonded precisely $90^{\circ}$ apart.

The geometrical integrity of a verification specimen is often unchecked and used as unblemished. Although extreme care may have been exercised during specimen machining, handling, and inspection, imperfection could remain undetectable by instruments such as shadowgraph which has its own limitations in resolution and accuracy. Therefore, it is prudent to assume that an extremely small angularity may exist between the ends of a verification specimen. Despite the defect, it is possible to eliminate the effect of nonparallel specimen ends when the load-train is being aligned.

A personal computer (PC) program capable of data acquisition and alignment analysis has been developed, allowing a user to easily recognize various possible conditions of nonparallel compression interfaces. This program is intended to facilitate identification of the tilt of the upper compression interface and to assist in adjusting the four turnbuckles above the fixed compression anvil. This process is repeated as the specimen is rotated through the four positions. When load-train alignment is completed, the resultant force should locate on each of the four quadrants as illustrated in the bottom row of Fig. 7, showing approximately equal amount of eccentricity and same angular position with respect to gage No. 1 .

Figure 8 shows the load-strain response curves for the four strain gages with gage No. 1 oriented at position A. All strain readouts were reset to zero at load-free condition. The initial diversion of strain readouts at $0.25 \mathrm{kN}$ indicated that the ends of the verification specimen were slightly nonparallel. The curves beyond $0.75 \mathrm{kN}$ are virtually linear and parallel to each other, indicating that the specimen was uniformly compressed.
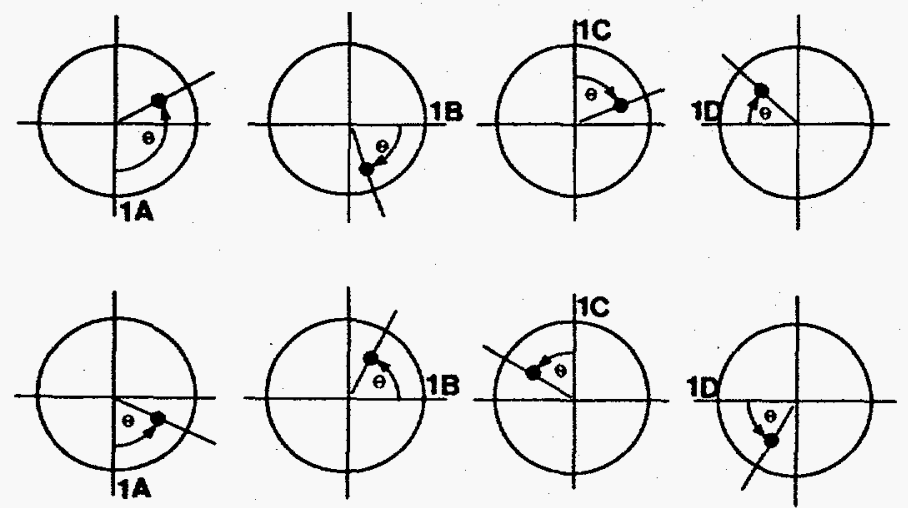

FIG. 7 - TOP ROW INDICATES NONPARALLEL INTERFACES; BOTTOM ROW INDICATES REASONABLY GOOD PARALLEL INTERFACES. "1A, 1B, 1C, and 1D" INDICATE GAGE NO. 1 ORIENTED TO POSITIONS A, B, C, AND D, RESPECTIVELY.
Bending strain in terms of percentage of the average strain at each level of loading was calculated and plotted in Fig. 9. Four alignment evaluations were performed with gage No. 1 oriented to four different positions as indicated. High percentage of bending at low loads is due to the low average strain. Since the amount of eccentricity will cease to increase when both ends of the verification specimen become parallel, the percentage of bending should, in theory, approach to a small number as load increases. Figure 9 shows that the percentage of bending decreased to $<5 \%$ as loads exceed $1.75 \mathrm{kN}$, which meets the condition recommended for uniaxial tensile testing per ASTMC1273-94. The intrinsic eccentricity that excludes the effects of specimen imperfection was then calculated using linearized test data, which show that the load-train is capable of uniform compressive loading with low bending less than $1.5 \%$.

\section{TEST RESULTS AND DISCUSSION}

A grade of hot-isostatically-pressed silicon nitride ceramic, engineered and marketed commercially as $\mathrm{GN}-10$ by AlliedSignal Ceramic Components, Torrance, Califomia, was tested in compressive

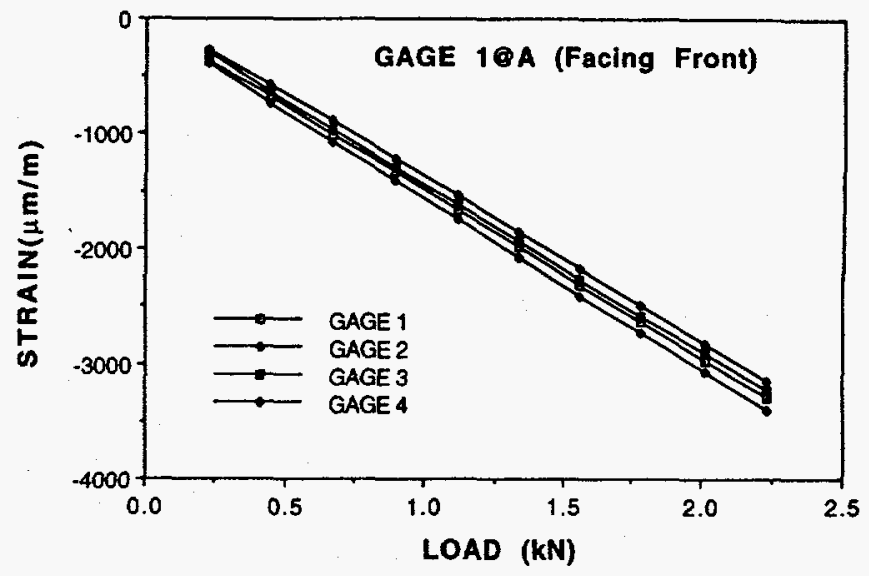

FIG. 8 - LOAD-STRAIN RESPONSE CURVES FOR FOUR STRAIN GAGES WITH GAGE NO. 1 ORIENTED TOWARD POSITION A.

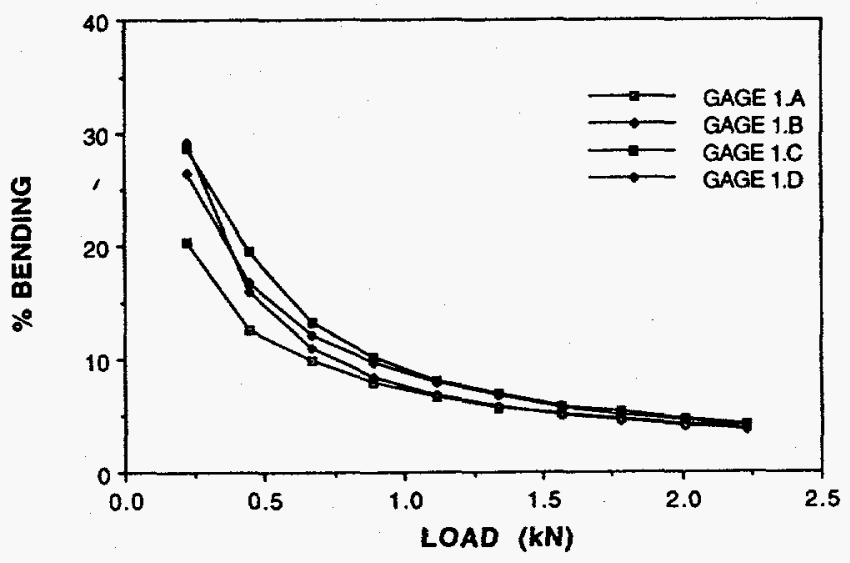

FIG. 9 - PERCENTAGE OF BENDING STRAIN AS A FUNCTION OF LOAD. 
creep. Results of a compressive creep test at $1300^{\circ} \mathrm{C}$ are shown in Fig. 10, which also shows previously reported tensile creep data (Ding, 1994) for comparison. Under an applied stress of $125 \mathrm{MPa}$, the tensile creep specimen ruptured in $15.2 \mathrm{~h}$ of testing with a creep rate of $3.76 \times 10^{-4} \mathrm{~h}^{-1}$ shortly before failure. The creep rate under the same stress in compression became reasonably steady after completing $\sim 100 \mathrm{~h}$ of testing with a creep rate of $5.33 \times 10^{-3} \mathrm{~h}^{-1}$, which was about three orders of magnitude lower than that under tension. The compressive stress was increased intermittently in steps of $25 \mathrm{MPa}$ each time the specimen completed a period of discernible steady-state creep. The creep behavior during the second leg of testing at -150 $\mathrm{MPa}$ was slightly erratic but the trend of creep deformation was discernible. Transient creep was observable following each load increment. Currently, the specimen has just completed a period of $-1500 \mathrm{~h}$ of testing at $250 \mathrm{MPa}$ with a creep rate of $-1.07 \times 10^{-6} \mathrm{~h}^{-1}$. Cursory examination indicated that the creep rate increased proportionally with the applied stress, suggesting that creep of $\mathrm{Si}_{3} \mathrm{~N}_{4}$ under compression may be promoted by a shearing mechanism. No indication of imminent failure has been observed and the load-train appears to be in stable condition.

\section{SUMMARY}

A unique load-train assembly was developed for testing a dumbbell shaped ceramic specimen in compression at high temperatures. Excellent load-train alignment is attributed to the self-aligning universal coupler which appears to operate reliably according to the basic design principles warranted by the definitive laws of hydrostatics and mechanics. Results of evaluation tests using a strain gaged

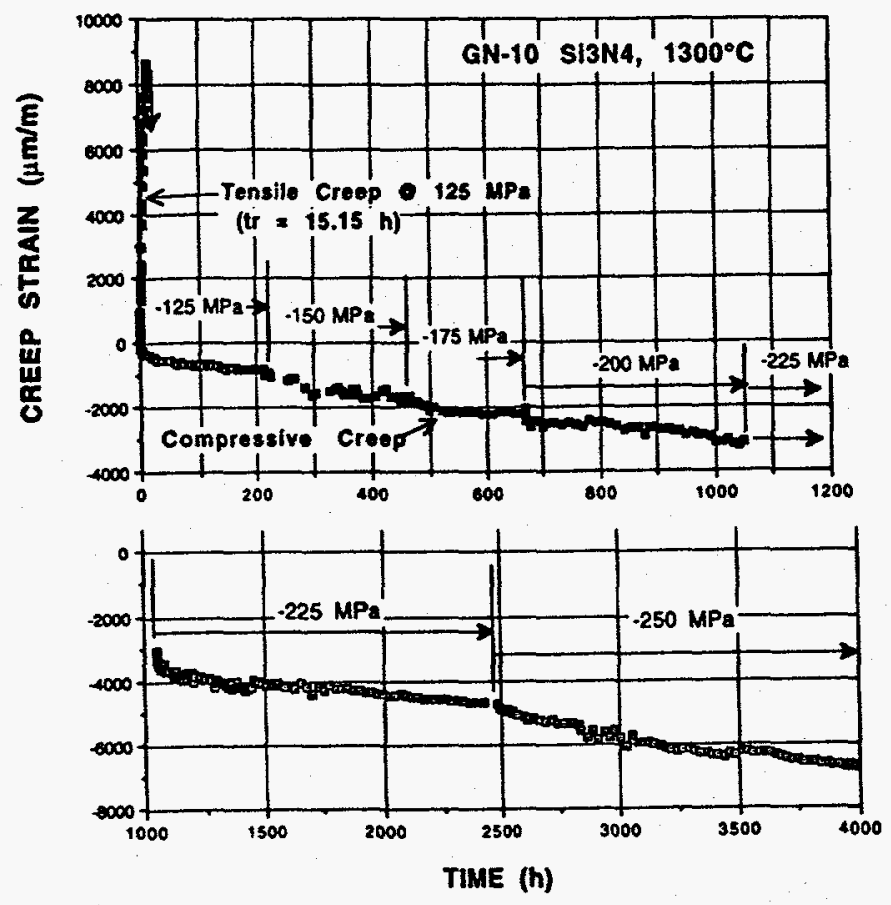

FIG. 10 - CREEP CURVES OF GN-10 $\mathrm{SI}_{3} \mathrm{~N}_{4}$ SPECIMENS TESTED AT $1300^{\circ} \mathrm{C}$ IN TENSION (RUPTURED IN $15.2 \mathrm{~h}$ ) AND IN COMPRESSION (DISCONTINUED AT 4,200 h). specimen indicated that specimen bending below $1.5 \%$ is routinely achievable with the use of the self-aligning coupler. A PC software program was developed to facilitate alignment and evaluation. An alignment method was discussed as how to eliminate the effect of using an evaluation specimen with slight inherent imperfections. Meaningful test data were obtained from an actual compressive creep test on a $\mathrm{Si}_{3} \mathrm{~N}_{4}$ ceramic specimen tested at $1300^{\circ} \mathrm{C}$ for a long period of time in excess of $4000 \mathrm{~h}$, demonstrating high reliability and dependability of the load-train system.

\section{ACKNOWLEDGEMENTS}

The authors thank Drs. A. A. Wereszczak and S. K. Iskander for reviewing the manuscript and providing many valuable suggestions.

This research was sponsored by the U.S. Department of Energy, Assistant Secretary for Energy Efficiency and Renewable Energy, Office of Transportation Technologies, as part of the Ceramic Technology Project of the Propulsion System Materials Program, under contract DE-AC05-960R22464 with Lockheed Martin Energy Research Corporation.

\section{REFERENCES}

Anderson, C. A., Wei, D. P., and Kossowsky, R., 1975, "Analysis of the Time Dependent Flexural Test," Deformation of Ceramics, R. C. Brandt and R. Tressler, ed., Plenum Press, New York, pp. 383-398.

ASTM, 1995, "Standard Practice for Tensile Strength of Monolithic Advanced Ceramics at Ambient Temperatures," C1273-94, Annual Book of ASTM Standards, Vol. 15.01, pp. 385-402.

Birch, J. M., Wilshire, B., Owen, D. J. R., and Shantaram, D., 1976, "The Influence of Stress Distribution on the Deformation and Fracture Behaviour of Ceramic Materials under Compression Creep Conditions," J. of Materials Science, Vol. 11, pp. 1817-1825.

Chuang, T. -J., and Wiederhorn, S. M., 1988, "DamageEnhanced Creep in a Siliconized Silicon Carbide: Mechanics of Deformation," J. of American Ceramic Saciety, Vol. 71, pp. 595-601.

Cohrt, H., and Thuemmler, F., 1985, "Creep of Reaction Bonded, Siliconized Silicon Carbide," International J. of High Technology Ceramics, Vol. 1, pp. 87-105.

Debschütz, K. D., Schneider, G. A., and Petzow, G., 1993, "Critical Evaluation of the Compression Creep Test," J. of American Ceramic Society, Vol. 76, No. 10, pp. 2468-2474.

Ding, J. L, Liu, K. C., More, K. L., and Brinkman, C. R., 1994, "Creep and Creep Rupture of an Advanced Silicon Nitride Ceramic," J. of American Ceramic Society, Vol. 77, No.4, pp. 867874.

Lankford, J., 1977, "Compressive Strength and Microplaticity in Poly crystalline Alumina," J. of Materials Science, Vol. 12, pp. 791-796.

Liu, K. C., and Brinkman, C. R., 1986, "Tensile Cyclic Fatigue of Structural Ceramics," Proceedings, 23rd Automotive Technology Development Contractors' Coordination Meeting, Dearborn, Michigan, October 21-24, 1985, SAE, Warrendale, PA, P-165, pp. 279-284.

Sines, G., and Adams, M., 1978, "Compression Testing of Ceramics," Fracture Mechanics of Ceramics, R. C. Bradt et al., ed., Plenum Press, New York, Vol. 3, pp. 403-434.

Tracy, C. A., 1987, "A Compression Test for High Strength Ceramics," J. of Testing and Evaluation, Vol. 15, No.1, pp. 14-19. 